\title{
Globalization, culture and ELT materials: a focus on China
}

Zhichang Xu

Correspondence: zhichang.xu@ monash.edu

Monash University, Melbourne, Australia

\begin{abstract}
In this paper, I shall discuss issues regarding globalization and culture in the context of English language teaching (ELT), with a particular focus on Chinese ELT materials in secondary schools in China. Globalization has a far-reaching impact on the foreign language education industry in China. Chinese learners of English view globalization positively as opportunities for geographical and social upward mobility. In addition, Chinese learners adopt a pragmatic approach to Chinese and foreign cultures in terms of negotiated multiculturalism based on a Yin Yang principle (Fang 2011, p. 34) of co-existence, mutual reinforcement and paradoxical unity. This paper reviews Chinese conceptualizations of globalization and culture as well as English as an International Language (EIL), and analyses ELT textbook materials for secondary schools in China. The analytical framework is based on current ElL principles and criteria for ELT materials (Sharifian 2009, McKay 2012, \& Matsuda 2012). Chinese secondary school English textbooks have been collected as data, and their analysis shows that 1) texts about cultures other than English (COTE) co-exist with texts of traditional Inner-Circle (Kachru 1982) cultures, 2) cross-cultural perspectives are represented in current secondary school English texts, 3) multiculturalism has been incorporated in the texts, 4) explicit efforts have been made in the compilation of text materials and relevant learning activities to cater for the needs of Chinese secondary students for learning English in the Chinese context, 5) texts that help raise awareness of world Englishes and local functionalities of English are included in the textbooks, and 6) the teachers' and students' relevant personal experiences and schemas are utilized and activated in the choice and design of the main and supplementary texts and related activities. I conclude the paper by arguing that the ongoing globalization and multicultural awareness, alongside the paradigm shift to teaching EIL in the Chinese context have engendered desirability for incorporating multicultural and multimodal ELT materials in China. It is, therefore, not only feasible but also natural and timely to focus on the local functionalities, i.e., local needs, functions and purposes, in the ELT materials, and this has significant implications for Chinese learners and teachers of English.
\end{abstract}

Keywords: Globalization; Culture; English as an International Language; ELT material; Chinese English learners

\section{Springer}

(c) 2013 Xu; licensee Springer. This is an Open Access article distributed under the terms of the Creative Commons Attribution License (http://creativecommons.org/licenses/by/2.0), which permits unrestricted use, distribution, and reproduction in any medium, provided the original work is properly cited. 


\section{Introduction}

In China, the notion of globalization (quanqiuhua) has been embraced since the 1970s when China proposed and implemented economic reforms and open-door policies. This was a time when concepts of 'global village', 'future shock' and the 'third wave' (c.f., Toffler 1970, 1980) were popular both domestically in China and overseas. Since then, China has been seeking to revitalize its 'global village' membership. Against this backdrop, English began to be extensively taught in schools replacing Russian and Japanese in their school curricula as a major school subject for 'foreign language' (waiyu) education. Earlier texts for learning English are either localized, including slogan-like texts of 'Long live Chairman Mao', or imported texts, e.g., the Aesop's Fables, and the Million Pound Note. In the 1980s and 1990s, the English textbooks that were commonly used in China mainly included texts written in the so-called 'standard' English expressing the cultural values of Americans or British. As a result of this, Chinese students were exposed to linguistic and cultural expressions and values that they did not have first-hand experiences with, and they could not have the opportunity 'to challenge the knowledge or put it to use in their immediate contexts' (Xu 2010, p. 176). Xu (2004, p. 68), therefore, proposes that textbooks in China should consider why Chinese students learn English, how they use English, and whom they should regard as language models.

Since the beginning of the century, Chinese ELT materials for secondary schools have been developed to incorporate both global and local Chinese cultures, specifically designed for Chinese learners of English. This new dimension in ELT material development is aligned with Chinese conceptualizations of globalization, culture and the changing profile of the English language, and the emerging Chinese variety of English (Xu 2010). In this paper, I shall analyse a new series of English textbooks adopted nationwide for senior secondary schools in China. The textbooks include five volumes of 'New Senior English For China' (Second Edition). These books are written and edited for secondary school students across China by the 'course book research team' affiliated to the People's Education Press. This paper analyses the texts included in the 'New Senior English for China' series from the perspective of Chinese conceptualizations of globalization, culture, and the emerging paradigm of EIL. Major research questions include whether the texts expose the Chinese secondary school English learners to diversities of English and cultures; what cultures are represented; and whether the texts help engage the Chinese students in using English, and provide opportunities for the students to associate their own Chinese cultures with other cultures. This paper shall start with a review of the conceptualizations of globalization, culture, and EIL. It shall then propose an analytical framework, followed by text analysis. I shall conclude the paper by arguing that the ongoing globalization and multicultural awareness, alongside the paradigm shift from teaching English as a foreign language to teaching EIL in the Chinese context have engendered desirability for incorporating multicultural and multimodal ELT materials in China. It is, therefore, not only feasible but also natural and timely to focus on the local functionalities, i.e., local needs, functions and contexts, in the ELT materials, and this has significant implications for Chinese learners and teachers of English. 


\section{Current conceptualizations of globalization, culture and EIL}

In this section, I shall review the current conceptualizations of globalization, culture and EIL, in particular how Chinese conceptualize these notions in relation to the spread of English in China, and the development of Chinese ELT materials.

\section{Globalization}

Globalization is an ongoing process that permeates almost all societies. Many scholars (e.g., Blommaert 2010; Eriksen 2007; Garrett 2010; McKay 2002; McKay \& BokhorstHeng 2008; Mufwene 2010; Schneider 2011; Scholte 2000) have explored the meanings and implications of 'globalization'. It is essential to understand the process of globalization in order to examine cultures and ELT materials in China, where an increasing number of people learn and use English for both intra- and inter-cultural communication. Globalization has been closely associated with global communication and mobility. However, people from different cultures conceptualize globalization differently, and their attitudes towards globalization also change over time.

One of the connotations of globalization, to an average Chinese, is Americanization. Since late 1970s, when English was re-introduced into the Chinese school curricula, Chinese learners of English have been increasingly influenced by American cultures, and become one of the major consumers of American cultural products, including Hollywood movies, Radio and Television programmes, fast food chains, American English teaching materials, and American English speakers as language instructors. Garrett's research (2010, p. 456) on the East-West contrastive analysis of globalization shows that people from different nations hold different views towards globalization, with China and the USA leaning towards more 'positive orientations' while the UK, New Zealand and Australia leaning towards more 'negative orientations'. According to Garrett (2010, p. 458), while people from the UK, Australia, New Zealand and Japan perceive globalization as 'global unity', Chinese tend to see it primarily as 'opportunity' coupled with 'cooperation' and 'change'. To a certain extent, the Chinese conceptualization of globalization as opportunity renders an explanation to the Chinese craze for English. English learning in China implies opportunities for geographical (going overseas) and social upward mobility (i.e., professional development and promotion), and it also symbolizes the removal of imposed territorial and ideological restrictions in the sense of 'liberalization' as defined by Scholte (2000, p. 16). Globalization as opportunity for a Chinese is also closely associated with progressiveness, modernity, and positive changes at an individual level and that of China as a developing nation.

Current literature on globalization reveals a wide range of connotations, including mobility (i.e., the flow of populations, commodities, and ideologies) (Blommaert 2010; Eriksen 2007; Garrett 2010; Mufwene 2010); blending and mixing of local, translocal and global cultures (Blommaert 2010; Eriksen 2007; McKay and Bokhorst-Heng 2008); 'local functionality' (Blommaert 2010, p. 44), 'super-diversity' (Blommaert 2010, p. 7), 'polycentricity' (Blommaert 2010, p. 60), and 'micro-hegemonies' (Blommaert 2010, p. 62); and the paradox of standardization (Eriksen 2007). I shall review these major connotations with a focus on Chinese cultures and ELT materials in China. 
1) Globalization as mobility

Mobility has been identified as one of the key features of globalization by Eriksen (2007). Migration, tourism, domestic and international conferences have thrust people to move around and settle either temporarily or permanently in new communities. Although these people bring with them their own languages and cultures, they also adjust themselves both linguistically and culturally in order to survive and thrive in the host communities. Blommaert (2010, p. 6) views migration as a 'change in the spatial organization of one's life in an enduring way'. It is 'enduring' in the sense that the nature of migration (i.e., the separation from the land of origin and one's own linguistic and cultural belongings) is likely to 'bring pressure to accommodate to the host society'. What adds to the endurance nature of migration is that in the context of globalization, according to Blommaert (2010), language forms are more mobile than before, patterns of use become less predictable, and all of the processes of mobility appear to display complex connections with language.

English learning in the context where English is not widely used is comparable to embarking on an enduring journey of migration. It is common for a Chinese to conceptualize globalization as mobility. To an average Chinese, 'mobility' that is associated with English learning may not exclusively mean migration, but it also means social or professional upward 'mobility' in terms of joining social elite groups, or seeking political, administrative and academic promotions. 'The Chinese, especially educated adults and university students, are motivated to learn English because they believe it will enable them to join an educated elite group and to have access to better jobs, more opportunities, and a wider world' (Xu 2010, p. 172). This connotation of 'globalization' also reflects Blommaert's ideologically 'acquirable imagery of the self as being in the world', because English learners in China are not simply learners of English, but symbolically they add a global element to their Chinese identities and become Chinese 'global' citizens.

Another aspect of mobility is closely related to the notion of space and time, which is subsequently related to issues of cultural 'dis-embedding' and 're-embedding' (Eriksen 2007, pp. 8-9), 'deterritorialisation' and 'territorialisation' (Blommaert 2010, pp. 45-46; Scholte 2000, pp. 15-17), and 'supraterritoriality' and 'transnationalism' (Garrett 2010, p. 449). Cultural 'dis-embedding' and 're-embedding' are two of the key features of globalization identified by Eriksen (2007, pp. 8-9). Dis-embedding 'includes all manners through which social life becomes abstracted from its local, spatially fixed context', while re-embedding is a countervailing process to territorialize a mix of local and global cultures through 'strong networks of moral commitment, concerns with local power and community integration, national and sub-national identity politics' (Eriksen 2007, pp. 8-9). Cultural dis-embedding and re-embedding processes are also closely related to deterritorialization and territorialization. The former stands for 'the perception and attribution of values to language as something which does not belong to one locality but which organizes translocal trajectories and wider spaces', while the latter refers to 'the perception and attribution of values to language as a local phenomenon, something which ties people to local communities and spaces' (Blommaert 2010, pp. 45-46). With 
globalization, the notion of language (de)territorialisation can become relative and fluid due to the increased velocity of movement of people and the unprecedented engagement of people in the virtual online world. 'Interaction across large distances enters into a complex relationship with local activity', therefore, the local has never been more closely connected to the global through the 'compressed time and space' in terms of 'supraterritoriality and translationalism' (Garrett 2010, p. 449). In the Chinese context, Xu's research (2009, pp. 123-124) shows that it can be hypothesized that there are varying 'micro-linguistic markets' co-existing in China, including a 'global linguistic market' where English is used for transnational communication; a 'supra-local market' where cosmopolitan Mandarin Chinese (often code-mixed with English) is used for trans-regional interaction among Chinese elite groups, and a 'local linguistic market' where dialects and vernacular Chinese are used in local communities. It should be noted that the 'micro-linguistic market' is not a geographical concept, but a conceptualization in relation to mobility, and dynamic communities of multiple language users in contemporary China. One implication of globalization as mobility for learning and using English in China is that ELT materials should reflect the dynamic linguistic and cultural complexities of a mobile world both in a global sense and the local reality. In other words, ELT materials should facilitate Chinese learners of English to raise their awareness that English has increasingly been used as an international language, and to cater for their needs of using English both locally and globally for intra- and international communication.

In addition, it should be noted that 'mobility' does not necessarily imply global symmetrical flow of populations and commodities. According to Mufwene (2010, p. 31), 'the players or partners involved in the relevant world-wide networks of interconnectedness and interdependence do not hold equal economic powers; it is the more powerful who control which populations and commodities (including languages) are transported more freely, and in which directions'. ELT materials as a carrier of cultures and ideologies play a crucial role in China, as learners of English generally have undiscerned access to English and its associated cultural content in their ELT classroom. The cultures and ideologies that the learners are exposed to may well determine how they perceive the language they learn. If the cultures are exclusively about the Inner Circle (Kachru 1982), then the learners tend to view English as a 'foreign' language. On the other hand, if the ELT materials are inclusive of a variety of cultures, and the texts include a variety of Englishes, then the learners may increase their awareness of EIL. In other words, English can be utilized as a tool to express different cultures and enhance multicultural identities of the learners. Eriksen (2007, pp. 8-9) points out that one of the consequences of globalization is the vulnerability in terms of protecting certain communities of people against unwanted flows. In the Chinese ELT context, English learners may not be empowered if they are only exposed to 'foreign' cultures and non-local linguistic forms through their ELT material. Such unwanted 'flows' of linguistic items and ideologies may demotivate the learners, and put them in a vulnerable position both as learners and users of English. To cater for the needs of Chinese learners of English, it is essential to be aware of the Chinese conceptualization of globalization as mobility. 
2) Globalization as cultural blending

Blommaert (2010, p. 60) points out that 'an important feature of globalization processes is the fact that they blend the local and the translocal in complex networks'. This blending involves both language and culture. In terms of language blending, people code-switch and code-mix when they communicate with others. In addition, they also transfer linguistic forms from their local languages to English. Cultural blending results from the increasing 'mutual dependence and transnational connections' and the 'instantaneous exchange of messages characteristic of the information era' (Eriksen 2007, pp. 8-9). McKay and Bokhorst-Heng (2008, p. 2) view globalization as a 'reformulation of social space in which the global and local are constantly interacting with one another'. They also argue that 'neither one should be afforded a dominant position'. This globalization as cultural blending implies that the English-speaking world that the ELT materials present should contain a blending of cultures, both local and international, so that learners can naturally blend their local experiences and cultures with those that are presented in the ELT materials.

3) Globalization as local functionality

It cannot be assumed that globalization is about everything-going-global. There has also been a concurrent localization process focusing on how a language operates at a local level. According to Blommaert (2010, p. 44), a language functions in a community precisely because it 'provides local meanings: meanings that provide frames for understanding the local environment, to categorize and analyse the (strictly) local world.' Even deterritorialized languages, e.g., English in China, should adapt to local functionalities. Blommaert (2010, p. 45) argues that 'when another language is introduced in a particular environment, it may as well be dysfunctional for it does not articulate the particular local meanings required for the sustenance of this environment'. If English in China is viewed exclusively as a 'foreign' language, then local cultures can hardly be encoded in English, e.g., using English in its Anglo-American sense to encode the Duanwu Festival, commonly known as the Dragon Boat Festival, and its associated cultural activities including making zongzi (angular rice balls wrapped in reed or bamboo leaves), drinking xionghuang (realgar) wine, and racing dragon boats. This conceptualization of globalization as local functionality implies that ELT materials should be developed to provide sufficiently localized English input to enable Chinese learners of English to function locally, e.g., describing and expressing their own local cultures and experiences for intra- and intercultural communication.

Mufwene (2010, p. 47) argues that localization can be regarded as globalization at a local or a regional level. He argues that 'however global the English language has become - in the sense of being a language that is spoken almost anywhere on our planet and permeates so many diverse domains of modern life - it will continue to indigenize everywhere, acquiring local characteristics in the same way it has done to date'. To incorporate texts of local cultures in local varieties of English into ELT materials is aligned with the process of globalizing English at the local or regional level. This localization process can sometimes go so far as to adopt local linguistic forms as in the case of McDonald's going local to adapt to local taste buds and using local languages for product marketing. 
4) Globalization as super-diversity

Globalization is the driving force for a global lingua franca, and English has been widely adopted as one. However, globalization does not necessarily lead to monolingualism or a monolithic 'global English'. Instead, Mufwene (2010, p. 50) argues that 'the differential evolution of English appears to be substituting a new form of diversity for an older one'. This new form of diversity also includes blended linguistic forms and cultures. Blommaert (2010, pp. 7-8) points out that 'super-diversity poses descriptive as well as theoretical challenges'. The descriptive challenge involves the spatial reconfiguration of the local and translocal, as well as real and virtual. 'All of this has effects on the structure and development of language repertoires and patterns of language use'. The theoretical challenge involves the stretching of 'the limits of existing frameworks for analysing and understanding multilingualism and the dynamics of language change'. In the context of ELT in China, this conceptualization of globalization as super-diversity can also be interpreted as the diversity in the needs of the learners, the demands for a variety of teaching pedagogy, e.g., grammar translation, communicative teaching, bilingual education and immersion, and the diverse ELT materials both for classroom use and extracurricular utilization, e.g., textbooks by different publishers, various reading and multimedia English learning materials, and super diverse preparation materials both in terms of quantity and quality for public tests, e.g., College English Test (CET) Band 4 and Band 6, Test for English Majors (TEM) Band 4 and Band 8, IELTS, TOEFL, and GRE.

The notion of super-diversity is also closely connected to micro-hegemonies, polycentricity, and normative complexes. Blommaert (2010, p. 62) defines 'microhegemonies' as a notion of 'restricted, niched hegemonies that co-exist with others in polycentric environments'. Taking the Chinese linguistic market (Xu 2009) as an example, the local, supralocal and global markets operate in a way that certain varieties of language(s) evolve and co-exist in super diverse communities in China. A localized variety of English co-exists with cosmopolitan Chinese in the global and supralocal linguistic markets, formulating micro linguistic and cultural hegemonies in relation to polycentric environments. Within these micro-hegemonies, certain beliefs, values and norms are shared and practiced. An example of such a microhegemony is the Chinese white-collar community in major cities such as Beijing, Shanghai and Guangzhou, where 'white-collar workers actively utilize resources from multiple languages (such as Standard English, Standard Mandarin, Chinese regional dialects, and Internet language), and the multimodal functions of the digital technologies' (You 2011, p. 409). The existence of micro-hegemonies implies poly-centricity. A polycentric context, according to Blommaert (2010, p. 61), is a 'context in which multiple normative complexes are simultaneously at work, but are of a different order'. Chinese ELT context is polycentric in the sense that English learning and teaching in China are contextualized in a heterogeneous society comprising multiple 'normative complexes' including local cultural norms, norms of the greater Chinese diaspora, and norms that have been introduced through ELT materials and other media forms. Blommaert (2010, p. 60) points out that 'given the intense polycentricity of learning environments and the fact that globalization processes develop at several different scale-levels, the issue of normativity becomes quite complex'. This suggests that ELT materials should not be oriented towards a 
monolithic norm mindset, but raise the awareness of the learners that multiple normative complexes have become the norm.

5) Globalization as heterogeneity

Another connotation of globalization is standardization. A common misperception about globalization and standardization is that globalization has led to a global village with a global English, and that commercial products and manufacturing processes have to go through various forms of standardization in order to achieve uniformity. To some extent, this can be true, because globalization entails a wide spread of English, and other notions, including 'internationalization' (the growth of international exchange), 'universalization' (the spreading of common objects and experiences to everyone) (Scholte 2000, pp. 15-17), and 'comparability and shared standards' (Eriksen 2007, pp. 8-9). However, Eriksen (2007, p. 10) also points out rightly that 'globalization does not entail the production of global uniformity or homogeneity. Rather, it can be seen as a way of organizing heterogeneity.' Indeed, in World Englishes, standardizing (or codifying) different varieties of English has been operating as a counteracting process leading to the heterogeneity of English . According to Mufwene (2010, p. 50), the heterogeneity resulting from the changing ecology of English features in: '1) the extent of the interactions the new speakers have had with speakers from the Inner Circle; 2) the specific languages English has come in contact with; and 3) the particular uses to which it has been put'. This conceptualization of globalization as heterogeneity enables Chinese to understand that the spread of English in China does not necessarily produce Chinese communities of uniform speakers of RP (Received Pronunciation) or GA (General American). Instead, it enables the local variations of English in China to continue to thrive. English is increasingly seen as either a 'local practice' or a language for 'translingua franca' communication (Pennycook 2010, pp. 682-684). The 'worldliness of English', in Pennycook's terms (2010, p. 681), may not simply be 'a matter of grammatical or lexical variation', but of 'cultural and ideological difference'. As far as ELT materials are concerned in the Chinese context, pluralizing cultures and Englishes can only be the first step towards addressing issues of super diversity under new conditions of globalization. A further step will have to be considered in terms of how the teachers and learners make use of the ELT materials so that their own language ideologies, cultural identities and local language practices also play an integral part in decoding and encoding the additional language of EIL both locally and globally. Situated and contingent ways of compiling ELT materials to address the heterogeneous nature of Chinese learners, teachers, and ELT pedagogy are what globalization as heterogeneity implies for English language education in China.

\section{Cultures, ELT materials and English as an International Language}

Globalization has various connotations, as discussed in the section of 'Globalization as mobility', however, according to Garrett (2010, p. 457), 'it is the culture category that is the most salient'. Byram (1988, p. 82) defines culture as knowledge which is 'shared and negotiated between people', and 'much of that knowledge is symbolically expressed in artefacts and behaviours and is formulated as rules, norms, expectations, as moral and legal codes, as proverbs, as parental injunctions to children'. Sharifian (2011, pp. 8-11) interprets 
culture in terms of schemas, including 'event,' 'role,' 'image' 'proposition' and 'emotion' schemas. Event schemas are abstracted from our experience of certain events, e.g., funerals and weddings; role schemas include knowledge about social roles which denote sets of behaviours that are expected of people in particular social positions; image schemas are iconic images that are readily imagined in relation to physical or social experiences, e.g., the image schema of a 'building' associated with the 'foundation of a nation', or the 'path' image associated with a straight path mapped onto ideologies as in 'the path to God'; proposition schemas are abstractions which act as models of thought and behaviour, e.g., marriage is enduring; and emotion schemas are complex configurations of feeling states and scenarios by reference to certain events or situations, e.g., 'shame' and its associated circumstances can be culturally specific. This notion of culture as schema renders a practical framework for textbook material analysis.

Fang (2011, pp. 27-31) has reviewed different paradigms of culture including 'static' and 'dynamic' paradigms. The 'static paradigm' assumes that 1) the complex phenomenon of culture is captured through simplification; 2) nationality or nation state is adopted as the basic unit of analysis; 3) cultural differences, cultural clashes, and cultural collisions are seen essentially as a problem; 4) cultures can be analysed in bipolar cultural dimensions along which each national culture is given a fixed indexing; 5) value is the most crucial component of culture, and 6) culture is concepturalised as stable over time. Fang (2011, pp. 28-29) points out that this static paradigm is essentially a 'pre-globalization and pre-Internet phenomenon', and it is incapable of capturing cultural dynamics in a globalizing society or dealing with intra-cultural diversity as well as cultural change over time. The 'dynamic paradigm' of culture centres around intercultural interaction, and it focuses on 'negotiated culture', and 'multiple cultural identity' (Fang 2011, p. 29). In the dynamic paradigm, cultural differences are seen essentially not as a problem but as an opportunity for learning and knowledge transfer, in which cultures are 'negotiated, compromised, embraced, and transferred' (Fang 2011, p. 30).

In light of the dynamic paradigm, Fang (2011, p. 31) has also proposed a Chinese 'Yin Yang' perspective on culture.

According to the Yin Yang philosophy, all universal phenomena are shaped by the integration of two opposite cosmic energies, namely Yin and Yang. Yin represents the 'female' energy, such as the moon, night, weakness, darkness, softness, and femininity; while Yang stands for 'male' energy, such as the sun, day, strength, brightness, hardness, and masculinity. The white dot in the black area and the black dot in the white area connote coexistence and unity of the opposites to form the whole. (Fang 2011, p. 31)

The Yin Yang principle suggests the underpinnings of 1) co-existence, 2) mutual reinforcement, and 3) dynamic and paradoxical unity (Fang 2011, p. 34). The implications of the Chinese notion of culture as yin and yang for ELT materials for Chinese learners are likely to be that 1) texts about different cultures can co-exist; 2) they can be used locally to the advantage of the Chinese learners to reflect on their own cultures; and 3) they provide Chinese learners and teachers opportunities to reinforce their dynamic multi-cultural awareness and identities. 
There are two views regarding the impact of globalization on culture. One is the homogenization and the other is hybridization of cultures. Garrett (2010, pp. 448-449) associates cultural homogenization with 'cultural imperialism, westernization, or Americanization'. He summarizes that some scholars hold the view that the global distribution of television programs, cinema, and other western cultural media products 'carry and spread the ideology and values of their creators and will ultimately replace the cultures in which they are distributed, while other scholars hold the view that western cultural commodities become 'localized or hybridized, and adapt to local tastes' so that their associated ideology and cultural value systems can be ignored or perceived differently in their new contexts. Over the past three to four decades, Chinese ELT materials have been developed to reflect the homogenization view, with a recent propensity towards the hybridization of cultures in the English texts for Chinese learners.

Taking culture as 'an endlessly recursive process of meaning making and meaning taking', Gray (2010, p. 715) views ELT textbooks as 'cultural artefacts', which serve to make English mean in particular ways. Gray (2010, p. 730) also points out that 'as with all cultural artefacts, textbooks are products of the cultures which produce them'. Yuen categorizes cultures that are represented in ELT material into four aspects, including products, practices, perspectives, and persons. 'Language can be considered an artefact or a system of code (products) used, to signify thoughts (perspectives), for communication (practices), by different people (persons)' (Yuen 2011, p. 459).

English has evolved into different varieties, and it has become distinctly English as an International Language. According to McKay (2002, p. 5), EIL is 'a language of wider communication both among individuals from different countries and between individuals from one country'. McKay (2006, pp. 120-121) points out further that 'cultural knowledge often provides the basis for the content and topics that are used in language materials and classroom discussions. Which culture to use in instructional materials needs to be carefully considered in reference to the teaching of an international language'. Sharifian (2009b, p. 2) regards EIL as 'a paradigm for thinking, research and practice' and he emphasizes that 'as a paradigm, EIL calls for a critical revisiting of the notions, analytical tools, approaches and methodologies within the established disciplines such as sociolinguistics of English and TESOL.' Matsuda (2012, p. 7), on the other hand, conceptualizes teaching EIL as 'preparing English learners to become competent users of English in international contexts.'

As far as the shift from teaching EFL to teaching EIL is concerned in the Chinese context, Xu (2002, pp. 233-237) proposed six changes over a decade ago regarding Chinese ELT perceptions and practices. These include (1) EIL should equally be associated with the cultures of all speakers of English; (2) Chinese English learners should incorporate their own Chinese norms and values and use EIL for local as well as international communication; (3) multilingual competent users should be regarded as models in the Chinese ELT classroom; (4) Chinese learners and teachers should be exposed to varieties of English to raise their awareness of EIL; (5) Chinese ELT classroom should be closely connected to the Chinese societies in terms of the use of English; and (6) Professional ELT teachers of multilingual backgrounds, both local and international should be employed for classroom teaching. Some of these changes have already taken place in the classroom. In terms of ELT materials for Chinese learners of English, the current textbooks that are used in senior secondary schools have shown new tendencies 
of involving Chinese learners as integral participants of a global EIL community, but in its virtual (imagined) sense. A number of scholars, e.g., Matsuda (2012), McKay (2012), have researched on the EIL teaching materials, curricula and principles. In terms of ELT material development for TEIL, the following criteria have been discussed, (1) the localization of English materials for local learners; (2) the exposure of the learners to different varieties of English, (3) the intercultural awareness of the learners in relation to the use of English and the learners' needs for English; (4) the promotion of multiculturalism; (5) the opportunities provided for the learners to associate their own needs and cultures. The following section will adopt the conceptualizations of globalization and culture that have been outlined above, and the criteria for EIL material development to analyse the current Chinese senior secondary school English textbooks. The main purpose of this analysis is to find out whether currently adopted English textbooks reflect the current conceptualizations of globalization and culture, and whether they meet the criteria for EIL material development.

\section{Chinese senior secondary ELT textbook data analysis}

For this paper, I have collected a full set of textbooks that are currently used in the Chinese nationwide secondary schools. The books include five volumes of 'New Senior English For China'. They were published by the People's Education Press of China in 2007. The books under investigation are their $10^{\text {th }}$ impression, published in July 2011. Each volume contains five major units. Within each of these units, there are separate sections including functional items, structures, reading, writing, and workbook. All the texts in the five volumes, including supplementary reading texts and text-based activities have been thoroughly investigated. The main focus is on how these texts and activities reflect on current conceptualizations of globalization, culture and EIL. In particular I have looked at how the texts cater for the needs of Chinese secondary school English learners, in terms of whether the texts enable them to associate their own daily life activities and cultures.

In the following section, I shall analyse the texts based on the observations and themes I have developed while processing the data. These observations include: 1) texts about cultures other than English (COTE) co-exist with texts of traditional inner-circle cultures, 2) cross-cultural perspectives are represented in English textbook series under investigation; 3) multiculturalism has been incorporated into the texts, 4) explicit efforts have been made in the compilation of text materials and relevant learning activities to cater for the needs of Chinese secondary school students for learning English in the Chinese context; 5) texts that help raise awareness of world Englishes and local functionalities of English are included in the textbooks; and 6) the teachers' and students' relevant personal experiences and schemas are utilized and activated in the choice and design of the main and supplementary texts and related activities.

\section{Co-existence of cultures other than English (COTE) and Inner-circle cultures}

Globalization instantiates itself in cultural blending, and this coincides with the Chinese Yin-Yang cultural perspective. In the five volumes of the textbook series, the majority of the texts, i.e., over $80 \%$, serve as examples where different cultures as reflected in the texts co-exist. For example, Book 1 unit 5 contains a text in the form of a personal 
account by Elias, describing how Nelson Mandela helped him deal with issues in his personal and professional life with regards to the equal rights between black and white people. Apart from Nelson Mandela, other 'heroes' including both Chinese and other nationalities have also been included in the pre-reading activity. These include William Tyndale of Britain, Norman Bethune of Canada, Sun Yat-sen of China, Mohandas Gandhi of India, and Neil Armstrong of the USA. Another example of cultural blending is Book 2, Unit 1. It deals with cultural relics. The images of 'cultural relics' as shown in the text include a Chinese Ming Dynasty vase, the Indian Tah Mahal, an ivory dragon boat, and the Chinese Mogao Caves. The text is 'in search of the amber room', known as a joint effort of German and Russian craftsmen. This unit is a case in point regarding the co-existence of cultures that do not originally belong to Inner-circle English-speaking cultures, e.g., China, India, Russia and Germany.

Similar examples also include Book 2, unit 5, where the text introduces western music (band) culture to Chinese learners. The first paragraph of the text poses a number of questions, e.g., Have you ever wanted to be part of a band as a famous singer or musician? Do you sing karaoke and pretend you are a famous singer like Song Zuying or Liu Huan? The text involves Chinese learners and their music cultures, although the main body of the text introduces Monkees, which is an American music band.

Book 3, Unit 1 is also a good example of the co-existence of global cultures in English texts. The text is about 'festivals around the world'. The festivals that have been discussed include 'Festivals of the Dead' (including the Japanese Obon, the Mexican Day of the Dead, and the Western holiday of Halloween), 'Festivals to Honour People' (including the Chinese Dragon Boat Festival, the American Columbus Day and the Indian national festival to honour Mohandas Gandhi), 'Harvest Festivals' (including the Western Harvest and Thanksgiving festivals, the European traditions of celebrating harvests, and the Chinese and Japanese moon-associated mid-autumn festivals), and not surprisingly 'Spring Festivals' (including the Chinese Spring Festival, and western carnivals, Easter, and Japan's Cherry Blossom Festival). The supplementary reading is more of a 'manifesto' of the co-existence of Chinese and Western cultures, in which a 'sad love story' was depicted, about a Chinese girl who missed her date on a Valentine's Day evening making the boy frustrated. The text encourages cross-cultural comparison in that this modern day Valentine story is interwoven with a classical Chinese love story about two traditional Chinese lovers being cruelly separated by the Milky Way, meeting each other only once a year by crossing the River on a bridge constructed by magpies with their wings.

Even when traditional and modern cultures that are commonly classified as belonging to the Inner-circle English speaking countries are presented, there are always explicit efforts either in supplementary reading or follow-up activities to involve the Chinese learners and their own cultures. For example, Book 3 unit 3 comprises of two scenes of Act I of the play based on a short story by Mark Twain, 'the Million Pound Bank Note'. This text presents certain cultural conflicts between two of the main Inner-Circle countries about a bet between two wealthy brothers, Roderick and Oliver, with a young American businessman from San Francisco, Henry Adams, involved, who at the moment was lost in London. The text reveals some of the traditional, and also stereotypical, cultural values about class, wealth, and how the British and Americans see each other (e.g., the British restaurant owner says 'it is well-known that Americans 
like to eat a lot'). One of the follow-up tasks for the Chinese learners is to work in pairs to continue writing the play. This task is designed in such a way that it involves the learners' own cultural values in relation to the cultures that are reflected in the text.

The above examples show that it is common in the Chinese English textbooks to have different cultures co-existing in the texts. This also conforms to the Chinese conceptualizations of globalization as cultural blending, and culture as co-existence in their Yin-Yang cultural philosophy. In addition, these texts also confirm McKay's (2002, p. 128) notion of 'a sphere of interculturality', in which Chinese learners learn about other cultures as a basis for reflecting on their own.

\section{Fostering cross-cultural and global perspectives of the Chinese learners of English}

Globalization also means mobility and opportunities for Chinese learners of English to become global citizens. Chinese learners see cultural differences as opportunities. The textbook series offers cross-cultural and global perspectives, and embraces cultural differences as opportunities for cross-cultural understanding. The texts are often narrated from a Chinese perspective, engaging Chinese learners in the interaction between global and local cultures. For example, Book 2 Unit 2 contains a significant text in terms of cross-cultural communication. It is about an 'imaginary' interview between Pausanias (a Greek writer about 2,000 years ago) and Li Yan (a Chinese volunteer for the 2008 Olympic Games). It is an interesting text cross-culturally, because the 'interview' text is not just between two characters from different cultural backgrounds, but also across time about 2000 years apart. Another example is Book 3 Unit 5 about Canada as a country of the 'True North'. Even if this text is exclusively about the Canadian landscape and cultures, it is narrated by two Chinese school girls, who were visiting Canada, and travelling on the 'True North' cross-Canada train. In this case, the InnerCircle cultures have been (re)presented from a cross-cultural (i.e., Canadian and Chinese) perspective.

Book 4 Unit 4 is about variations in 'body language' across cultures. The text is presented in a first person perspective of a Chinese university student about meeting International Exchange Students at the Beijing Capital International Airport. They meet and observe different customs for greeting each other. The international students are from Columbia, Britain, Japan, Canada, Jordan, and France. The text has also explicitly discussed practices of body language, and concluded by saying that 'studying international customs can certainly help avoid difficulties in today's world of cultural crossroads'. This reinforces the Chinese learners' willingness to embrace cultural differences as opportunities for cross-cultural understanding.

\section{Incorporation of Chinese variety of English (Chinese English) into the texts}

One of the EIL material development criteria, as discussed earlier in the paper, is the localization of English materials for local learners. This localization of English also means the use of Chinese English in the texts by the Chinese writers for the Chinese English learners. For example, Book 1 Unit 4 is about 'earthquakes'. The text 'a night the earth didn't sleep' is a good example of using English to describe a Chinese past event. The text is not written in the first person Chinese perspective, but it is in Chinese English, 
because of the Chinese event, image, and emotion schemas. There is also some 'proposition' schema, e.g., even after describing 'one of the greatest earthquakes of the $20^{\text {th }}$ century' in which 'the number of people who were killed or seriously injured reached more than 400,000', the text writer proposes that 'all hope was not lost', and 'the army organized teams to dig out those who were trapped and to bury the dead', and 'slowly, the city began to breathe again.' What is worth noticing here also includes the Chinese People's Liberation Army (PLA) 'image' schema, as great rescue fighters, under Chinese government leadership, in coping with natural disasters of such scales.

Another example of the incorporation of Chinese English into the texts is Book 4 Unit 2. The text is 'working the land', and it introduces 'a pioneer for all people', Dr. Yuan Longping, who worked and researched for 5 decades trying to grow super hybrid rice that has a high output. This text is a typical example of Chinese English, showing the Chinese learners how English can be used by Chinese to describe Chinese people in the Chinese context without reference to other non-Chinese cultures and role schema.

Book 5 Unit 4 is another example of Chinese English. The main text 'My first work assignment' is a 'dialogue' between a Chinese graduate (Zhou Yang) and his new boss from China Daily (an English newspaper based in Beijing), about his first job assignment as a reporter. This dialogue, inauthentic as it were, shows that English is not only just a 'written' language in the Chinese context, but also a 'spoken' one. In addition, the interaction is between two Chinese English speakers, without other non-Chinese involved, demonstrating that English can be used for intra-cultural/national communication for exclusive 'local' purposes. The supplementary text shifts from the dialogue in the main text to a third person descriptive story about how the protagonist in the main text had his first front page news article published. This text is localized in that English is used exclusively in a local Chinese professional setting. Sharifian's (2009a, pp. 249250) research shows that there are advantages of using local culture content as ELT materials, because 'it minimizes the potential of marginalizing the values and lived experiences of the learners', and more importantly, 'source culture content does not place local teachers in the difficult position of trying to teach someone else's culture'.

\section{Catering for the needs of Chinese secondary school English learners}

Secondary school English learners in China age between 12 and 18, and they learn English as a school subject. They may also have extracurricular activities or tutorial classes for improving their English proficiency, but the English classroom is the main venue where they are exposed to English. At teenage years, these secondary school students are usually curious about the English-speaking world. They have an imagined community where English is used, and they also enjoy reading stories in English that are of an imaginary nature. The textbook series has a considerable number of texts that are specifically selected or written to cater for the needs for Chinese teenage readers. For example, Book 1 Unit 1 'Anne's Best Friend' is about a teenage girl, Anne, and her Jewish family hiding from German Nazis during WWII. The whole story is about Anne living in her imaginary world of making a 'friend' with her own diaries, named 'Kitty'. The supplementary text of Book 2 Unit 2 is the 'story of Atlanta,' a Greek princess, and how a young man, named Hippomenes had won her love through a 'race' (a theme related to the main text about Olympic Games). Such texts present the students a mobile world where English can be used to describe things in 
the past, at present and in the future, with interactions between Chinese and people of non-Chinese backgrounds. Another example is Book 2 Unit 3 about 'computers'. This topic is nothing new to Chinese teenagers. However, it is written as a narrative from the perspective of a personified character of a 'computer' about its development from a 'calculating machine' to a modern-day personal computer. There is no explicit cultural perspective in the text, but the text has been made interactive with Chinese teenage readers.

The power of 'imaginary' world also plays a huge part in the supplementary reading text in Book 2 Unit 5, where a music band called Freddy the Frog getting all the fame and popularity and then decided to leave Britain and return to the lake. In this case, English is used in a fantasized world, and this helps the Chinese teenagers learn and use the language in an imagined community. Another example of an imagined world where Chinese teenagers are involved is the text of Book 5 Unit 3 entitled 'Life in the future'. It is about 'First Impressions' of a Chinese school boy, Li Qiang, travelling in a time capsule to a world of AD 3005, writing to his mum and dad about his first impressions of the future world. The supplementary reading, also using first person voice, describes an amazing imaginary world of a space station in which alien creatures live, work and interact with human space scientists. Here, English is taught to and learned by Chinese learners, not just for getting acquaintance with the outside world, both English speaking and non-English speaking, but also for associating the learners' own lives in an imaginary world. It makes the Chinese learners implicitly feel that English can be bended to their own needs, and it is not explicitly attached to any specific English speaking cultures. The texts as discussed in the above examples show the flexibility that cultures can be disembedded and re-embedded in the imaginary world to cater for the needs of Chinese teenage learners.

\section{Awareness of world Englishes, and global variation and change of cultures}

Another criterion for EIL text development is whether the learners are exposed to different varieties of English, and whether they are made aware of the superdiversity of cultures. A case in point in the textbook series regarding awareness of world Englishes is Book 1 Unit 2. This unit deals with the topic of 'World Englishes' explicitly, with a title of 'English around the world'. The reading is a brief historical account of the development of English, which touches upon topics of English change and variation, with explicit mention of British English, American English, Australian English, as well as Englishes in South Asia, including India, Singapore, Malaysia, and countries in Africa such as South Africa. This reading ends with a statement and a question, i.e., 'Today the number of people learning English in China is increasing rapidly. In fact, China may have the largest number of English learners. Will Chinese English develop its own identity? Only time will tell'. One claim in the reading is worth rethinking, that is, 'native English speakers can understand each other even if they don't speak the same kind of English' (Book 1, p. 10). The example that is provided is 'British Betty: Would you like to see my flat? American Amy: Yes. I'd like to come up to your apartment', and this example seems to be insufficient to support the above claim. However, in the supplementary reading 'Standard English and Dialects', the proposition that 'Believe it or not, there is no such thing as standard English' reflects the paradigm shift of English. 
It is sensible to include a text (i.e., Book 1 Unit 2) to introduce to Chinese learners the concept of World Englishes. However, it may take more than a simple text to raise the students' awareness of World Englishes. The textbook series has made a good effort to include texts of Chinese English and a considerable number of texts about other cultures. This may implicitly help Chinese students to be aware of the different varieties of English. At this stage, it appears that focus has been laid on the different expressions between British English and American English. For the students to gain a better awareness of the variation and change in World Englishes, more texts about different cultural schemas (e.g., event, role, image, emotion and proposition), cultural metaphors and cultural categories (Sharifian 2011) should be selected or written for the revised editions of the series.

\section{Relevance to the students' own Chinese experiences, and local functionalities}

The textbook series has done well in relating the texts to the Chinese secondary school learners' own experiences, and local functionalities. At the very beginning (i.e., Book 1 Unit 1) of the series, it has been very clear that learners are provided with opportunities either through texts or text-related activities to associate with their own personal experiences, e.g., one of the 'reading and writing' tasks in Book 1 Unit 1 is that the students are instructed to write a reply letter to a student from Huzhou Senior High School about his 'problem' of not being able to communicate with his peers, and feeling lonely. The role schema as set out in the task projects local characters such as 'Miss Wang' and 'Xiao Dong'. This helps students compose situated responses in relation to their own cultural experiences using English as a medium for written communication.

Another example of students associating their own cultures and practices is that the text of 'Standard English and Dialects' is immediately followed with a pair-work discussion task, e.g., 'The Chinese language also has many dialects. Work in pairs and make a list of the ones you and your partner have heard'. In Book 1 Unit 3, there is a small section of 'Reading for Fun' towards the end of the unit. It is an English translation of a well-known Chinese classical poem by Li Bai. To Chinese learners, it serves as an immediate trigger to activate their Chinese poem schema, as part of their first language literacy practices is to memorize classical Chinese poems, particularly those that were written in the Chinese Tang and Song dynasties.

Other examples involving the Chinese learners' own schema and experiences include Book 2 Unit 4. The text is about 'wildlife protection'. The warming up activity is a closely relevant task, as it is about a 'report on some endangered wildlife in China', including Panda, Milu deer and South China tiger. In addition, the text Book 3 Unit 2 deals with the competition between two Chinese restaurants (one serving barbecued mutton kebabs, roast pork, stir-fried vegetables and fried rice, and the other serving plain rice, raw vegetables, fruit and water). The two restaurant owners met and discussed their menus and they decided to serve a balanced menu with food full of energy and fibre. This text appeals to Chinese learners because the food items that are included in the text relate to Chinese food, and the students can easily associate their own diets with the menus described in the text, and also activate their restaurant schema based on their dining out experiences. 
What the above analysed texts have in common is that they all have an explicit focus on local functionalities. English fulfils multiple functions in the Chinese context, with regards to Chinese learners of English. These functions include: 1) a tool for Chinese learners to improve their 'foreign language' literacy; 2) a language through which Chinese learners gain access to other cultures and worlds beyond their local premises; 3) a language that can be fully adopted and bended to serve their own purposes of describing their own life events, in the past, at present, and in the future; 4) a language that can be used in professional settings in the Chinese context; and 5) a language to extend their world from realities to imaginations.

\section{Implications and conclusion}

The review of the meanings of globalization and culture, and the analysis of the textbook data have implications for ELT textbook writers as well as teachers and learners of English in a global EIL context.

As far as ELT textbook writers are concerned, it is important to be aware that the notions of globalization and culture can be interpreted differently in different cultures. The selection and composition of English texts for EIL instruction should be based on the current conceptualizations of globalization and culture. A wide range of texts should be selected or composed to reflect the current scenarios of mobility, cultural blending, local functionalities, super-diversity, and heterogeneity in the globalized EIL paradigm.

It is also essential that ELT teachers be aware that the cultural paradigm is not static. Teachers may avoid linearizing a language-nation-culture perception. In classroom teaching, it can be suggested that English teachers customize ELT materials so as to direct learners to understand that cultures co-exist, and that cultural differences are opportunities for raising cross-cultural awareness. In addition, there has been a paradigm shift from TEFL to TEIL in the Chinese and other Expanding Circle ELT context. It can also be suggested that teachers make an explicit effort to associate teaching and learning content and activities with the students' own experiences and cultural schemas.

As far as learners of English are concerned, it can be suggested that their own experiences and schemas be always made relevant to English learning. English, in the Chinese context, may not have to be learned exclusively for use in the future to interact with native speakers of English. Therefore, it is essential that learners associate with their own cultural schemas actively in the learning process, and focus on the use of English in local settings as well as for international communication.

It is worth pointing out that there are limitations of this textbook study in that it analyses only one textbook series among a number of others used in China. In addition, this study focuses primarily on what is in the textbook itself. To find out how the textbook materials are actually used and implemented in the classroom in China, it can be anticipated that classroom based research regarding the relationship among globalization, culture, and Chinese ELT materials should be conducted in due course.

In conclusion, throughout the paper, I have explored meanings of globalization and culture in relation to ELT and Chinese learners of English, with a particular focus on ELT materials in secondary schools in China. Chinese learners of English perceive globalization and the spread of English in China positively as opportunities for geographical and social upward mobility. In addition, Chinese learners adopt a pragmatic 
approach to the co-existence of Chinese and non-Chinese cultures. Taking Chinese conceptualizations of globalization and cultures, and EIL as frameworks, I have analysed ELT textbook materials for secondary schools in China. The data analysis shows that 1) texts about cultures other than English (COTE), including Chinese cultural texts, co-exist with texts of traditional inner-circle cultures, 2) cross-cultural perspectives are represented in current secondary school English texts; 3) multiculturalism has been incorporated in the texts, 4) explicit efforts have been made in the compilation of text materials and relevant learning activities to cater for the needs of Chinese secondary students for learning English in the Chinese context; 5) texts that help raise awareness of world Englishes are included in the textbooks; and 6) the teachers' and students' relevant personal experiences and schemas are utilized and activated in the choice and design of the main and supplementary texts and related activities. The ongoing globalization and multicultural awareness, alongside the paradigm shift to teaching EIL in the Chinese context have engendered desirability for incorporating multicultural and multimodal ELT materials in China. It is, therefore, as the current secondary English textbook data analysis testifies, not only feasible but also natural and timely to focus on the local learners as the legitimate users of English in the ELT materials, and this has significant implications for textbook writers and editors, as well as learners and teachers of English.

Competing interests

The author declares that he has no competing interests.

\section{Acknowledgements}

I wish to acknowledge the constructive comments provided by Prof. Farzad Sharifian and Prof. Sandra McKay. All remaining inadequacies in the paper are my own responsibility.

Received: 15 March 2013 Accepted: 14 May 2013

Published: 25 June 2013

\section{References}

Blommaert, J. 2010. The Sociolinguistics of Globalization. Cambridge: Cambridge University Press.

Byram, M. 1988. Cultural Studies in Foreign Language Education. Clevedon, Philadelphia: Multilingual Matters.

Eriksen, TH. 2007. Globalization: the key concepts. Oxford, New York: Berg.

Fang, T. 2011. Yin Yang: A New Perspective on Culture. Management and Organization Review 8(1): 25-50.

Garrett, P. 2010. Meanings of 'Globalization': East and West. In The Handbook of Language and Globalization, ed. N Coupland, 447-474. Maldden, Oxford, West Sussex: Wiley-Blackwell.

Gray, J. 2010. The Branding of English and The Culture of the New Capitalism: Representations of the World of Work in English Language Textbooks. Applied Linguistics 31(5): 714-733.

Kachru, BB (ed.). 1982. The Other Tongue: English across Cultures. Urbana: University of Illinois Press.

Matsuda, A. 2012. Introduction: Teaching English as an International Language. In Principles and Practices of Teaching English as an International Language, ed. A Matsuda, 1-14. Bristol, Buffalo and Toronto: Multilingual Matters.

McKay, SL. 2002. Teaching English as an International Language: Rethinking Goals and Approaches. Oxford, New York: Oxford University Press.

McKay, SL. 2006. ElL Curriculum Development. In English in the World: Global Rules, Global Roles, ed. R Rubdy and M Saraceni. New York: Continuum.

McKay, SL. 2012. Teaching materials for English as an international language. In Principles and practices of teaching English as an international language, ed. A Matsuda, 70-83. Bristol, Buffalo, Toronto: Multilingual Matters.

McKay, SL, and WD Bokhorst-Heng. 2008. English in an era of globalization, International English in its Sociolinguistic Contexts: Towards a Socially Sensitive Pedagogy, 3-17. New York: Routledge.

Mufwene, SS. 2010. Globalization, Global English, and World English(es): Myths and Facts. In The Handbook of Language and Globalization, ed. N Coupland, 31-55. Maldden, Oxford, West Sussex: Wiley-Blackwell.

Pennycook, A. 2010. The future of Englishes: One, many or none? In The Routledge Handbook of World Englishes, ed. A Kirkpatrick, 673-687. London and New York: Routledge.

Schneider, EW. 2011. English into Asia: From Singaporean Ubiquity to Chinese Learners' Features. In Contours of English and English Language Studies, ed. M Adams and A Curzan, 135-156. Ann Arbor: University of Michigan Press.

Scholte, JA. 2000. Globalization: a critical introducation. Hampshire and New York: Palgrave Macmillan.

Sharifian, F. 2009a. Cultural Conceptualizations in English as an International Language. In English as an International Language: Perspectives and Pedagogical Issues, ed. F Sharifian, 242-253. Bristol, Buffalo and Toronto: Multilingual Matters.

Sharifian, F. 2009b. English as an International Lanquage: An Overview. In English as an International Language: Perspectives and Pedagogical Issues, ed. F Sharifian, 1-18. Bristol, Buffalo and Toronto: Multilingual Matters. 
Sharifian, F. 2011. Cultural Conceptualizations and Language (Vol. 1). Amsterdam, Philadelphia: John Benjamins Publishing Company.

Toffler, A. 1970. Future Shock. New York, Toronto, London, Sydney, Auckland: Bantam Books.

Toffler, A. 1980. The Third Wave. New York, Toronto, London, Sydney, Auckland: Bantam Books.

Xu, Z. 2002. From TEFL to TELL: Changes in Perceptions and Pactices: Teaching English as an International Language (EIL) in Chinese Universities in P. R. China. In Englishes in Asia: Communication, identity, power and education, ed. A Kirkpatrick, 225-244. Melbourne: Language Australia Ltd.

Xu, Z. 2004. From English to Englishes: Changes in College English Textbooks for Chinese Students. In The Proceedings of the 9th English in Southeast Asia Conference, ed. F Alip, 57-69. Yogyakarta, Indonesia: Sanata Dharma Unversity Press. Xu, Z. 2009. Linguistic, cultural and identity issues in Englishization of Putonghua. In Englishization in Asia: Language and Cultural Issues, ed. K-k Tam, 119-139. Hong Kong: Open University of Hong Kong Press.

Xu, Z. 2010. Chinese English: Features and Implications. Hong Kong: Open University of Hong Kong Press.

You, X. 2011. Chinese white-collar workers and multilingual creativity in the diaspora. World Englishes 30(3): 409-427.

Yuen, K-M. 2011. The representation of foreign cultures in English textbooks. ELT Journal 65(4): 458-466.

doi:10.1186/2191-5059-3-6

Cite this article as: Xu: Globalization, culture and ELT materials: a focus on China. Multilingual Education 2013 3:6.

\section{Submit your manuscript to a SpringerOpen ${ }^{\circ}$ journal and benefit from:}

- Convenient online submission

Rigorous peer review

- Immediate publication on acceptance

- Open access: articles freely available online

- High visibility within the field

Retaining the copyright to your article

Submit your next manuscript at $\boldsymbol{s p r i n g e r o p e n . c o m ~}$ 